\title{
Percepção Ambiental e Climática de Alunos de Escolas Públicas de Itajubá - MG
}

\author{
Environmental and Climatic Perception of Students from Public Schools of Itajubá - MG
}

\author{
Weslley Vieira dos Santos ${ }^{1,} \bowtie$ iD, Michelle Simões Reboita ${ }^{2} \bowtie$, Roger Rodrigues Torres ${ }^{3} \bowtie$ \\ Gabriela Marques di Giulio $4 \square$
}

\author{
1 Universidade Federal de Itajubá, weslleyvieiramg@gmail.com, \\ https://orcid.org/0000-0001-9421-6360 \\ 2Universidade Federal de Itajubá, mireboita@gmail.com \\ 3Universidade Federal de Itajubá, torres.fisico@gmail.com \\ 4Universidade de São Paulo, ggiulio@usp.br
}

Recebido (Received): 19/08/2018

Aceito (Accepted): 23/05/2019

\begin{abstract}
Resumo: A percepção é o processo no qual o indivíduo assimila os estímulos externos, os internaliza por meio do processo cognitivo e a eles atribui significado. Nesse sentido, a percepção ambiental e climática pode ser compreendida como a forma pela qual os indivíduos entendem os fenômenos naturais que se manifestam no seu cotidiano. O objetivo do presente estudo é conhecer a percepção ambiental e climática de estudantes de escolas públicas municipais de Itajubá-MG. Foram selecionadas quatro escolas, duas localizadas na área rural e duas localizadas na área urbana do município. Adotou-se uma estratégia metodológica quantiqualitativa, com aplicação de questionários e observação dos estudantes ao longo do ano de 2016. As análises apontaram que os estudantes não se reconhecem como integrantes do sistema atmosférico e que os estudantes inseridos no meio rural não demonstraram possuir uma percepção ambiental e climática diferenciada dos estudantes de escolas urbanas, no que se refere a descrição de elementos do meio natural e atmosférico.
\end{abstract}

Palavras-chave: Ensino Fundamental; Crianças; Topofilia; Topofobia

Abstract: Perception is the process by which the individual assimilates external stimuli, internalizes them, through the cognitive process, and assigns them meaning. Hence, environmental and climatic perception is the form what individuals understand natural phenomena that happens in their daily life. Accordingly, the objective of this study is to get to know the environmental and climatic perception of fifth-year elementary students of municipal public schools in Itajubá, MG. Four schools were selected to perform the study, two in the rural area and two in the urban area of the municipality. A quantitative-qualitative methodological strategy was adopted through the application of questionnaires and observations performed throughout the year 2016, to attend both the objectives of the university extension project Amigos do Clima and this perception research. The analyzes indicated that presented the same difficulty: to perceive themselves as belonging to the atmospheric environment; and that students that come from rural areas do not necessarily have a more accurate environmental and climatic perception than students attending schools in the urban area.

Keywords: Elementary School; Children; Topophilia; Topophobia

\section{Introdução}

Existem diversas linhas de pesquisa que estudam a interação do homem com o ambiente, sendo o estudo da percepção uma delas. A percepção pode ser entendida como um processo cognitivo no qual o homem capta, assimila, processa e atribui significado aos estímulos externos (TUAN, 2012). Para Oliveira (2002), ao se abordar a percepção ambiental, é preciso estabelecer diferenças entre sensação, percepção e cognição. A sensação pode ser entendida como a realização da percepção por meio de um órgão corporal; já a percepção possui a conotação de apreensão de uma realidade sensível, na qual se atribui um significado; enquanto a cognição é o processo no qual se conhece e se constrói o objeto de conhecimento.

Tuan (2012) atribui, às relações afetivas e de pertencimento do indivíduo com o meio, o conceito de "topofilia" e, em contraponto, utiliza o conceito de "topofobia" para interpretar as relações de medo e 
preconceito desenvolvidas pelo indivíduo em relação ao ambiente. A percepção pode variar de acordo com o sexo e com a idade do indivíduo. Oliveira (2002) exemplifica que a criança, ao brincar nos ambientes externos, em meio à natureza e ao tempo atmosférico, recebe estímulos constantes e variados, trabalhando e enriquecendo sua percepção do espaço, bem como desenvolvendo sua sensibilidade, coordenação motora, mente e criatividade.

Nesse contexto, se inseriu o projeto de extensão universitária "Amigos do Clima" que teve como um de seus objetivos conhecer a percepção ambiental e climática de crianças de escolas públicas do município de Itajubá-MG. Esse projeto foi desenvolvido entre 2015 e 2017, com a ideia de ser um facilitador no ensino de ciências naturais nas escolas, estimulando o interesse de estudantes por este assunto, em especial, pela Meteorologia. Cerca de 160 crianças participaram do projeto. Estiveram envolvidas no projeto duas escolas localizadas na área urbana (Escola Municipal Desembargador Francisco Pereira Rosa e Escola Municipal Professora Isaura Pereira dos Santos) e duas na área rural (Escola Municipal Ana Junqueira Ferraz e Escola Municipal Olímpio José Joaquim). Durante a execução do projeto Amigos do Clima, os alunos das referidas escolas responderam questionários que foram à base do presente estudo (REBOITA et al., 2017).

O objetivo do presente estudo foi conhecer a percepção ambiental e climática dos estudantes dessas quatros escolas municipais de Itajubá, na busca de compreender melhor as relações existentes entre as crianças e seu meio. Destaca-se que esse estudo é inédito na região sul mineira.

Os estudos realizados por Ribeiro e Affonso (2012), que avaliaram a percepção ambiental de alunos do ensino fundamental, e por Fogaça e Limberger (2014), que buscaram entender a percepção ambiental e climática de alunos de ensino fundamental, nortearam o presente estudo.

Dentre os diversos estímulos ambientais que influenciam o homem, destaca-se o tempo atmosférico e o clima, que exercem grande influência na percepção humana (RIBEIRO; ZAVATTINI, 2016). Para Specian, Paiva e Rocha (2016) "o clima é um agente presente e atuante na vida das pessoas". Inegavelmente, influenciando também na perspectiva de lazer do homem, e, por tanto, no seu âmbito emocional e afetivo, gerando e quebrando expectativas: como a de um final de semana na praia, ou uma trilha nas montanhas, frustrados, devido à ocorrência de uma chuva imprevista.

Outro aspecto a ser valorizado decorre da variação da percepção conforme com o sexo do indivíduo. Gobo et al. (2016) avaliaram a percepção climática e do conforto térmico de homens e mulheres em Santa Maria - RS, e observaram diferenças entre elas, tendo as mulheres apresentado maior desconforto térmico do que os homens.

Quanto à percepção ambiental e climática da criança, destaca-se o estudo de Fogaça e Limberger (2014) que avaliaram a percepção de crianças de três escolas da cidade de Toledo-PR. O estudo concluiu que os alunos da escola da área rural possuem maior percepção dos fatos relacionados ao meio ambiente, sobretudo, por seu ambiente de convívio ser o campo, mantendo relações mais próximas com a natureza e, também, pelo fato de a maioria se tratar de filhos de agricultores, que dependem totalmente das condições do tempo para o cultivo e o manejo da terra. Os autores também apontaram que os estudantes do meio urbano possuem uma menor percepção ambiental e climática, ficando muito claro, o desinteresse desses participantes pelo assunto.

Sartori (2014) atenta que o clima percebido pode diferir do clima real, resultante da análise climatológica objetiva baseada em séries sistemáticas e homogêneas de dados corretamente registrados. Em corroboração, Specian, Paiva e Rocha (2016) identificaram que, na percepção dos moradores de Arenópolis-GO, o clima está mudando, isto é, chovendo menos. Entretanto, os dados de chuvas analisados apontam que não se trata de diminuição da quantidade de chuvas, mas uma variação de sua distribuição ao longo do ano.

Outro aspecto que não pode ser desconsiderado é a influência dos meios de comunicação no processo da percepção. As inúmeras informações veiculadas pela mídia induzem, sobretudo os jovens, a consolidarem certezas e posicionamentos sobre determinados assuntos, como, por exemplo, mudanças climáticas. Rodas e Di Giulio (2017) ressaltam a importância do papel da mídia para a compreensão pública das mudanças climáticas, bem como sua responsabilidade em tentar representar as questões complexas relativas às mudanças climáticas, relacionando-as às experiências da vida moderna, considerando incertezas, controvérsias, riscos e ameaças, além de projeções futuras e possibilidades de enfrentamento. Nesse sentido, Barros e Pinheiro (2017) realizaram um estudo sobre a percepção do adolescente em relação às mudanças climáticas e ao cuidado ambiental. Os autores afirmam que a percepção desse fenômeno é construída pelos jovens de maneira indireta, sendo influenciada, por exemplo, por informações fornecidas por professores em sala de aula, representações em livros, jornais, internet, e na mídia em geral. Esse estudo apontou uma confusão na percepção dos adolescentes quanto às mudanças climáticas, de modo que os alunos as percebem 
como um problema ambiental genérico e as confundem com outros problemas, como a poluição pelo acúmulo de lixo.

Nessa esteira, o presente estudo buscou, utilizando-se de metodologias consolidadas na literatura, conhecer a forma como crianças de escolas públicas interpretam o meio no qual estão inseridas.

\section{Métodologia}

\subsection{Caracterização da Área de Estudo e Espaço Amostral}

O presente estudo foi desenvolvido na cidade de Itajubá, localizada no sul de Minas Gerais, conforme demonstrado na Figura 1. Segundo dados do Instituto Brasileiro de Geografia e Estatística (2016), no ano de 2016 foi estimada uma população total em Itajubá de 96.523 habitantes; sendo registradas no mesmo ano 10.769 matrículas no ensino fundamental e 3.583 matrículas no ensino médio.

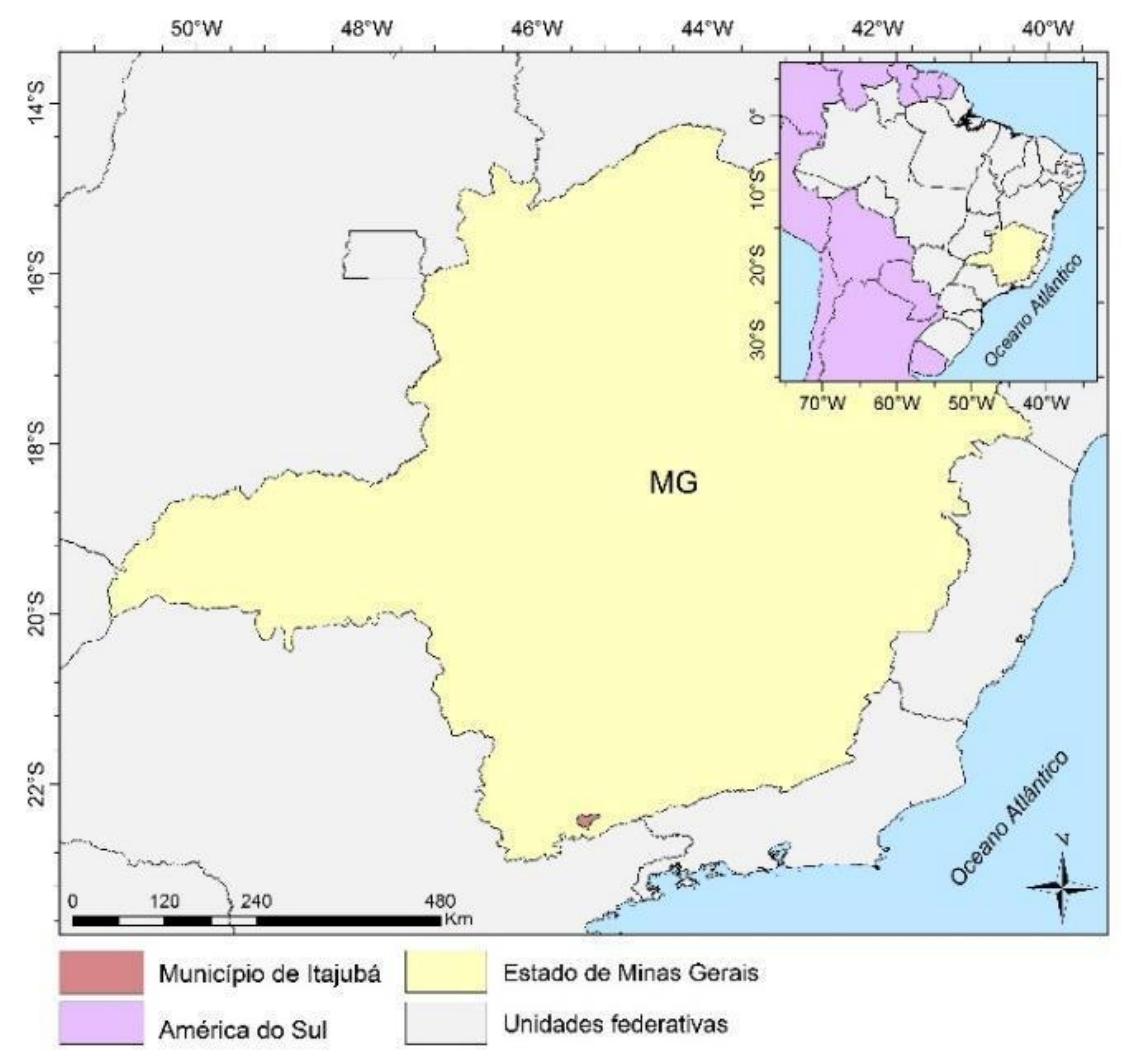

Figura 1: Localização do município de Itajubá em relação ao Brasil e ao Estado de Minas Gerais - MG.

De acordo com a classificação climática de Köppen (KOTTEK et al., 2006), o clima de Itajubá é o Cwa, isto é, clima temperado úmido com inverno seco e verão quente (REBOITA et al., 2013; REBOITA et al., 2015. A temperatura média do mês mais quente é superior a $22^{\circ} \mathrm{C}$; ; o total médio anual de chuvas é de 1.458 $\mathrm{mm}$, sendo que cerca de $80 \%$ desse valor ocorre entre os meses de outubro a março (REBOITA et al., 2015).

Para a seleção das escolas que participariam do projeto Amigos do Clima e pesquisa em percepção ambiental e climática, foi deita uma análise dos Programas de Intervenção Pedagógica do Ensino Fundamental do Município de Itajubá-MG. Feita análise, se concluiu que o quinto ano do ensino fundamental seria o grupo escolar mais adequado para participar do projeto e da pesquisa, pois desenvolveriam, ao longo do ano letivo, competências como: reconhecer unidades de capacidade (litro e mililitro) e identificar os principais climas do Brasil, o que facilitaria a participação nas atividades do projeto. O critério para seleção das escolas foi à distribuição geográfica de cada uma delas. A utilização desse critério se deu pelo fato de que, uma das fases do Projeto Amiga do Clima, consistia na mediação de água da chuva pelas crianças em suas respectivas residências, de modo que a seleção das escolas localizadas em pontos extremos da cidade permitiria uma compreensão mais ampla da distribuição espacial do volume de chuva no município de Itajubá-MG (REBOITA et al., 2017).

Observando esse critério, foram selecionadas 4 escolas, duas na área urbana e duas na área (Figura 2). 


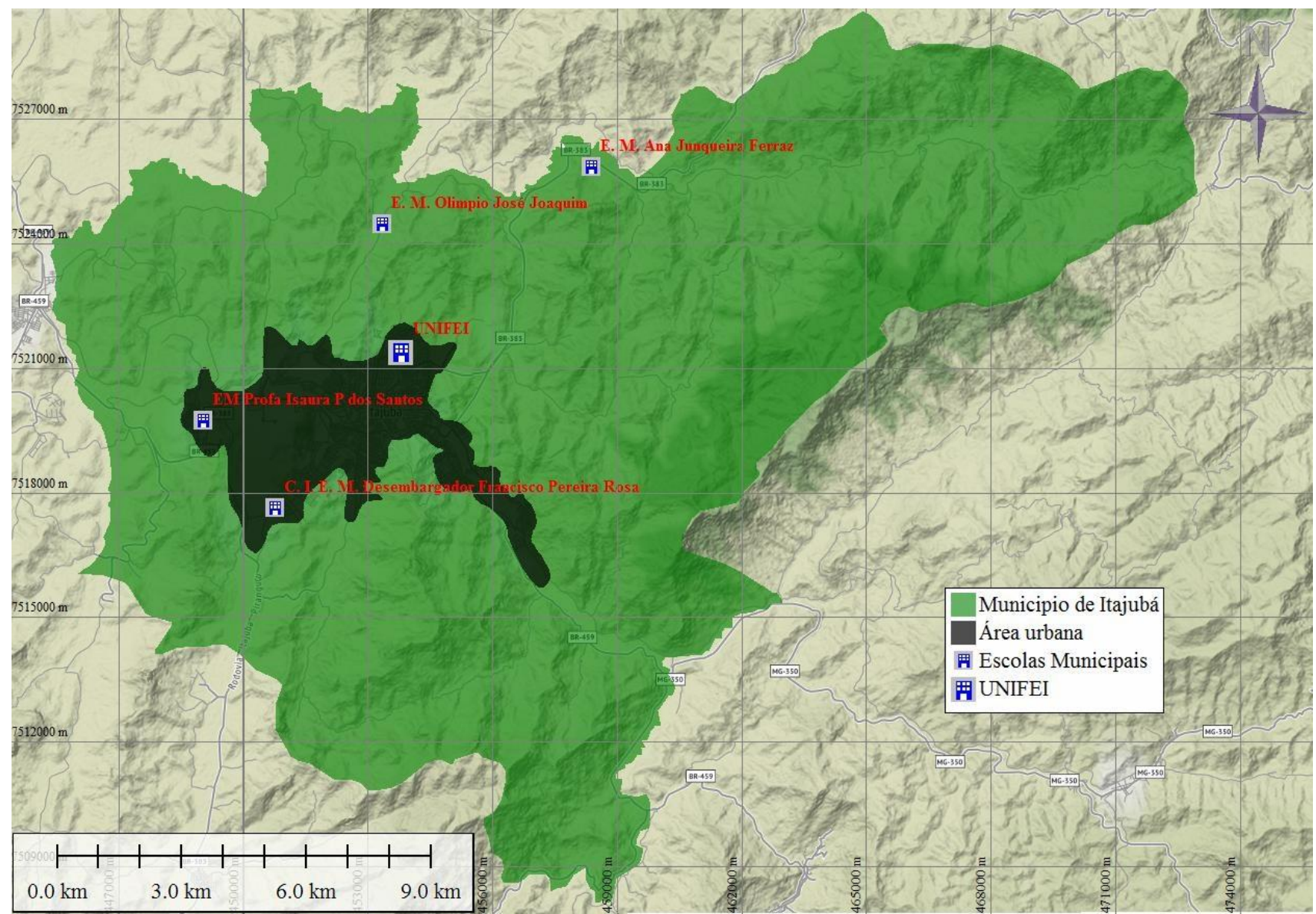

Figura 2: Localização geográfica das escolas selecionadas no município de Itajubá-MG; e da Universidade Federal de Itajubá (UNIFEI), instituição de ensino que desenvolveu o projeto Amigos do Clima. Figura Elaborada por Alexandre Germano.

\subsection{Instrumentos}

O instrumento base para a coleta da amostra do estudo foi o questionário. Foram aplicados dois questionários: o primeiro no início do mês de fevereiro de 2016 e o segundo no início do mês de dezembro de 2016. O primeiro questionário, de caráter quantitativo buscou identificar características socioeconômicas, culturais e o nível de conhecimentos específicos dos alunos. Os resultados desse trabalho estão apresentados em Santos e Reboita (2017). O segundo questionário de caráter qualitativo, de que trata este artigo, buscou conhecer a percepção ambiental e climática das crianças.

Os questionários foram submetidos ao Conselho de Ética em Pesquisa com Seres Humanos, nos termos da resolução no 466, de 12 de dezembro de 2012, do Ministério da Saúde, e obteve aprovação.

A amostra foi constituída de 160 crianças, distribuídas nas quatro escolas selecionadas. Essas crianças, com idades entre 9 e 12 anos, no ano de 2016 frequentavam o $5^{\circ}$ (quinto) ano de escolaridade do ensino fundamental. Foram excluídos da amostra os alunos que não foram à aula no dia da aplicação dos questionários, bem como os alunos que não apresentaram o Termo de Consentimento Livre e Esclarecido regularmente assinado pelo seu responsável legal, de modo que 142 alunos responderam ao questionário sobre percepção.

Durante a aplicação do questionário, as questões foram respondidas pelos alunos à medida que o pesquisador lia a questão e esclarecia o que estava sendo perguntado. Esse método se mostrou o mais adequado na aplicação do questionário, já que o objetivo da pesquisa não era identificar a capacidade de interpretação das questões por parte das crianças, e sim conhecer sua percepção ambiental e climática.

Para análise das entrevistas buscou-se identificar termos-chave, relacionados a manifestações atmosféricas, topofilia e topofobia (FOGAÇA; LIMBERGER, 2014). 


\section{Resultados e Discussões}

As perguntas formuladas no questionário são uma adaptação de algumas das questões utilizadas no estudo de Fogaça e Limberger (2014), que avaliaram a percepção ambiental e climática de alunos de escolas públicas. Essas questões versam sobre as experiências cotidianas dos alunos e a forma como eles se relacionam com seu ambiente. Além dessas perguntas, foram elaboradas questões para conhecer a percepção dos alunos quanto às mudanças climáticas.

Os 142 questionários aplicados nas quatro escolas foram numerados em ordem crescente: os questionários com numeração entre 1 e 19 contém as respostas dos alunos da Escola Municipal Olímpio José Joaquim; os com numeração entre 20 e 39, por alunos da Escola Municipal Ana Junqueira Ferraz; e os com numeração entre 40 e 89 por alunos da Escola Municipal Professora Isaura Pereira dos Santos; e os com numeração entre 90 e 142 por alunos da Escola Municipal Desembargador Francisco Pereira Rosa.

\section{Questão 1: Você tem o hábito de observar o céu?}

Na primeira questão, 95 crianças responderam que possuíam o hábito de olhar o céu, contudo não informaram com que frequência costumavam fazê-lo. Curiosamente, pouco mais da metade dos alunos da escola Ana Junqueira, da zona rural, afirmaram não ter tal hábito, o que aponta para a ideia de que não se pode concluir que todas as crianças que estão inseridas no meio rural estão mais atentas ao seu meio. No questionário 83, encontra-se a afirmação: "As vezes gosto de olhar os formatos das nuvens", demonstrando que no céu, são as nuvens que chamam a atenção desta criança. No questionário 111, o aluno responde: "Eu olhei para o céu ontem"; já no questionário 142, há uma resposta mais aplicada: "Só quando a lua tá cheia, porque ela ilumina o céu, não lembro o dia mas tenho a imagem na minha cabeça". Essa resposta demonstra o impacto que a beleza da lua causou nessa criança, de modo que ela não pode precisar o dia em que observou o céu noturno pela última vez, mas a imagem do satélite está registrada em sua memória, conforme afirma Tuan (2012), foi visto, assimilado, e recebeu carga emotiva, o que caracteriza o fenômeno da percepção e ocorrência da Topofilia, sentimento que se constrói pelo lugar onde se vive.

\section{Questão 2: O que você acha bonito no céu?}

Na segunda questão, 47 crianças responderam que o que mais achavam bonito no céu era: o sol, a lua, as estrelas e as nuvens. No questionário 81, encontra-se a seguinte resposta: "Eu acho a estrela, o sol, a nuvem, e a cor do céu e os pássaros", e no questionário 129: "Nuvens e pássaros", dos 142 questionários analisados, apenas nestes dois se encontram elementos da fauna, a referência aos pássaros caracteriza uma capacidade de perceber o meio conjuntamente as demais formas de vida, demonstrando um diferencial no processo perceptivo. No questionário 82: "Eu acho a noite bonita o céu e as estrelas", no questionário 99: "A cor do céu, o sol, de noite as estrelas" e no questionário 116: "as estrelas a lua e os planetas" a beleza do céu noturno é ressaltada pelas crianças, demonstrando encanamento, sobretudo, pelas estrelas. As nuvens também são o que no céu chama muito a atenção das crianças, no questionário 83, consta: "Tudo a cor o que as nuvens formam e as estrelas", no questionário 97: "as nuvens brancas o sol o céu azul", no questionário 108: "as figuras que as nuvens formam" e no 136: "Nuvens lindas". Uma resposta demonstrou o que talvez seja a influência das mídias ou de produtos da cultura na forma como a criança entende o meio ambiente, já que no questionário 112 não há informação se a criança teve contato direto com o fenômeno da neve, constando apenas: "A neve porque como é que sai gelo da atmosfera". Outra resposta única se encontra no questionário 132: "paisagens", o que pode se deduzir ser uma referência à vastidão do horizonte. Também singular foi à resposta no questionário 89: "Arco íris e Deus", demonstrando que a forma como esta criança interpreta o meio ambiente está intimamente relacionada com sua crença em Deus.

\section{Questão 3: Recorda-se de quando foi à última vez que parou para observar o céu? Quando foi?}

$\mathrm{Na}$ terceira questão, 81 alunos declararam que haviam olhado o céu ontem, antes de ontem ou especificaram uma data que equivalia a dois ou três dias anteriores à data em que foi aplicado o questionário. Destacam-se as respostas dos questionários de número 80, 83 e 99 que, respectivamente, afirmam: "Todos os dias eu olho o por do sol"; "Sempre eu olho, eu acho o céu muito bonito"; "Sim, ontem, não tinha estrelas". Nessas respostas, observa-se, pela forma com que essas crianças se expressam, a ocorrência de sentimentos topofólicos (TUAN, 2012). No questionário 99, inclusive, a criança detalha a ausência das estrelas na última noite. Outra resposta que merece destaque encontra-se no questionário 112: "A noite que acabou a força elétrica", demonstrando o quanto a vida moderna, repleta de mídias e luzes artificiais a todos aliena do 
mundo natural, de modo que a criança só se deteve para olhar o céu noturno, talvez, por falta de opção, devido à ausência de energia elétrica. Nesse sentido é a observação de Oliveira e Nunes (2007), que alerta para a ocorrência de um divórcio crescente entre a população e o meio físico, muito em decorrência da dinâmica da atualidade, que estimula o distanciamento entre pessoas e o mundo físico, pois estas vivem em um mundo artificial, quase virtual, sem tempo para observar as situações corriqueiras da atmosfera.

\section{Questão 4: Você já parou para pensar que você faz parte da atmosfera?}

$\mathrm{Na}$ quarta questão, 72 alunos afirmaram nunca ter parado para pensar se fazem parte da atmosfera. Nessa questão não houve respostas elaboradas. Talvez a palavra "atmosfera" tenha causado algum estranhamento nos alunos, já que não conseguiram relacionar a si mesmos com os aspectos atmosféricos. Na Escola Municipal Desembargador Francisco Pereira Rosa, 44 alunos afirmaram que já pararam para pensar na questão. Entretanto, não elaboraram respostas que revelassem conhecimento sobre o assunto.

\section{Questão 5: O que mais te chama atenção na atmosfera? (temperatura, vento, chuva, umidade, nuvens, raios, trovões).}

Na quinta questão, 61 alunos transcreveram os exemplos que constavam na questão, ou seja: temperatura, vento, chuva, umidade, nuvens, raios, trovões, preterindo um ou outro exemplo. As nuvens e a chuva são destacadas por sua beleza pelos alunos nos questionários 110: "Chuva, porque a gente pode ficar dentro de casa assistindo TV, e as nuvens porque elas são legais por causa do formato de cada uma"; questionário 115: "Chuva porque a chuva trás a água para nossa cidade"; questionário 122: "Nuvens, porque ela faz desenhos bonito"; e questionário 121: "A chuva por que eu acho muito interessante quando ela cai do céu e quando cai granizo". Uma criança, no questionário 80 , mencionou a combinação que muitas crianças conhecem cedo: "O sol e a chuva porque os dois juntos da o arco-íris", no questionário 116 uma criança descreve a beleza perigosa dos raios: "os raios porque o formato do raio é bonito" e no questionário 120, uma criança finaliza: "tudo, porque acho interessante".

\section{Questão 6: Você já percebeu que o tempo te atrapalhou em alguma atividade? Qual atividade? Por quê? (estava ventando forte, muito quente, muito frio, chovendo, a rua estava alagada).}

Na sexta sétima questão, 86 crianças apontaram que o tempo atrapalhou suas brincadeiras, provavelmente brincadeiras na rua, como se pode exemplificar pelo descrito no questionário 100: "Sim, porque eu fui caçar pokémons e choveu" e questionário 125: "Sim atrapalhou eu brincar na rua, muito quente chovendo". Entretanto, alguns alunos apontaram que o tempo foi responsável por terem que interromper atividades que realizavam no interior de suas residências, consta no questionário 76: "Sim, saiu o sinal da TV por causa do vento e da chuva", no questionário 120: "Eu ia assistir cumplicies de um resgate e começou a trovejar e minha mãe não deixou eu assistir". A resposta no questionário 110 , "Eu estava andando na cidade e aí começou a chover e nois teve que ficar dentro de uma loja esperando a chuva passar", relata um episódio que ficou registrado na memória da criança, que provavelmente representou a quebra da expectativa de um passeio, mesmo que temporariamente. Igualmente, no questionário 132 consta mais uma quebra de expectativa decorrente do tempo: "estava chovendo dai minha sala não foi a educação física".

\section{Questão 7: Sua casa já foi danificada por algum fenômeno do tempo? O que aconteceu na casa?}

Apenas 29 crianças das 142 respondentes declararam que sua casa já foi danificada pelo tempo na sétima questão. Também foi a minoria que descreveu o ocorrido quando ele aconteceu. No questionário 38 está descrito: "Sim, o muro caiu por causa da chuva muito forte mais isso aconteceu dia 4 de maio"; no 104: "Sim, saiu um monte de telhas e saiu um pedaço de antiga parabólica", no 120: "Sim, o raio caiu no padrão"; no questionário 125: "Porque alagou minha casa"; e no 129: "Sim rachaduras, vento forte, chuva". A descrição que consta no questionário 38 chama atenção, já que a criança especificou a data do fato, o que pode significar que o ocorrido a impactou, de modo a registrar na memória a data do evento traumático. Acontecimentos marcantes constam ainda nos questionários 120 e 125, sendo que neste último a criança usa a expressão "alagou", o que demonstra um nível diferenciado de conhecimento sobre o assunto, uma vez que a população itajubense, em geral, associa a ideia de enchente a qualquer caso em que haja acumulo de água devido às chuvas. Na palestra realizada durante a execução do projeto Amigos do Clima (REBOITA et al., 2017), os alunos tiveram a oportunidade de aprender as diferenças de inundação, enchente e alagamento. Segundo Tominaga, Santoro e Amaral (2011) a enchente ocorre com a elevação do nível da água no canal 
devido ao aumento da vazão, ao atingir a cota máxima, sem extravasar; a inundação ocorre quando a água do curso fluvial atinge a planície de inundação ou área de várzea e transborda; já o alagamento ocorre com o acumulo momentâneo da água em determinados locais, ocasionado pela deficiência do sistema de drenagem. O nível de participação das crianças durante esta etapa do projeto foi satisfatório, o que pode indicar que alguns conceitos transmitidos foram assimilados pelas crianças.

\section{Questão 8: Você tem medo do tempo? (raios, ventanias, chuva forte).}

$\mathrm{Na}$ oitava questão, 59 crianças declararam não ter medo do tempo. Parte considerável da amostra, 49 crianças, afirmaram ter medo de chuva forte, raios e trovões. Questionário 78: "Sim, cair um raio na minha casa em cima de mim"; questionário 83: "Não muito, mais tenho medo de chuva forte"; questionário 111: "sim, descarga elétrica por que tenho medo de morrer e também de levar choque"; questionário 102: "Não porque perto da minha casa tem um para raios". O Brasil é líder mundial na incidência de raios, que provocaram a morte de 1.790 pessoas entre o ano de 2000 e de 2014, sendo que a cada 50 mortes por raio no mundo, uma acontece no Brasil (BRASIL, 2016). Essas informações, veiculadas pelas mídias e provavelmente reforçada no âmbito social e da comunidade, aliados a própria observação do fenômeno pela criança, são elementos que compõem o processo perceptivo que constrói o medo de raios. Esse medo pode ser entendido como um sentimento topofóbico. A topofobia é o conceito desenvolvido por Tuan (2005) para interpretar as relações de medo e preconceito desenvolvidas pelo indivíduo em relação ao ambiente.

Outras respostas curiosas foram as de cinco alunos da escola Olímpio José, que declararam ter medo de tornados. Esse medo provavelmente se construiu à medida que os alunos assistiam ao noticiário, a filmes e desenhos, já que o fenômeno não é comum na região (até o momento não há descrição na literatura).

Ressalta-se que durante as palestras ministradas nas escolas, os alunos aprenderam o que é uma tromba d'água. O termo tromba d'água é utilizado pela população, em geral, para qualificar uma chuva muito intensa, quando, cientificamente, é utilizado para descrever um tornado sobre um corpo d'água. As imagens de trombas d'água expostas encantaram os alunos dessa mesma escola, que passaram a fazer inúmeras perguntas sobre o fenômeno, muitas vezes mirabolantes, como o que aconteceria se três trombas d'água se unissem e viessem para a terra firme. O episódio revelou o fascínio que determinados fenômenos naturais podem causar nas pessoas, sobretudo, nas crianças.

\section{Questão 9: Na sua casa, os seus familiares comentam que o clima está mudando?}

Na nona questão, 105 crianças afirmaram que seus familiares faziam afirmações correspondentes à mudanças no clima. Infelizmente, somente alguns alunos especificaram qual o membro da família fazia tais afirmações. O que se pode depreender das análises é que, os avós, são os que mais comentavam sobre o assunto. No questionário 114 consta: "Sim. Minha avó fala que agora o tempo é louco" o que parece ser uma expressão corriqueira no discurso de pessoas idosas. No questionário 121, a criança afirma: "sim meu avo sempre comenta isso comigo". Ruoso (2012) em seu estudo sobre a percepção climática de indivíduos que vivem no meio urbano de Santa Cruz do Sul - RS, estabeleceu que sua amostra seria composta por pessoas que residissem há mais de 20 anos na cidade, já que, para estabelecer um padrão climático é necessário, no mínimo, 30 anos de análise dos dados das estações meteorológicas. Os resultados demonstraram que a população, no geral, ofereceu respostas perceptivas relevantes, ficando evidenciada a percepção ambiental e climática, resgatando-se o conhecimento popular nas experiências no espaço vivido. Ante o exposto, há que se considerar que os idosos, ou seja, pessoas com mais de 60 anos, são os indivíduos mais adequados para falarem sobre suas percepções quanto a mudanças no clima. Isso, diferentemente de crianças, jovens e adultos, que não viveram o suficiente para reconhecer mudanças no clima, sendo sua noção de mudança climática construída mediante o estudo formal e a assimilação de informações veiculadas pelas mídias. Assim, as respostas dos alunos, quando registram que os avós são os que mais procedem a esses comentários, demonstra coerência.

\section{Questão 10: E você, acha que o clima está mudando?}

O estudo que avaliou a percepção ambiental e climática de crianças com idades entre 10 e 11, realizado por Fogaça e Limberger (2014), mostrou que a maioria delas não se sente pertencente ao meio atmosférico, não indica conhecimento sobre à dinâmica atmosférica e o sentimento predominante é o de medo em relação às manifestações atmosféricas. O estudo realizado por Barros e Pinheiro (2017) sobre a percepção do adolescente em relação às mudanças climáticas e o cuidado ambiental revelou que a percepção desse 
fenômeno é construída de maneira indireta, mediante contato com professores em sala de aula, leituras feitas em livros, em jornais e na internet, ou pela mídia em geral. Esses resultados são consoantes com 13 respostas obtidas na décima questão. No questionário 43, consta: "Não, mais na televisão na internet fala que o clima está mudando", no questionário 74: "Eu não sei mais minha mãe fala que o clima está mudando"; questionário 77: "Não. Porque eu não sabia o jornal que fala"; questionário 79: "Eu não sei mais ouvi fala que o clima esta mudando sim"; questionário 89: "eu não sei mais ouvi falar que o clima está mudando"; questionário 125: "Sim, porque na internet que o clima está mudando" questionário 130: "Sim sempre vejo na internet". Algumas crianças fizeram associação entre poluição e o aquecimento global, questionário 66: "Sim por causa da poluição e porque está mais quente", questionário 72: "Sim cada dia ta mais quente e a geleira fria derretendo porque é muita poluição no mundo". Outras crianças declaram que o clima está mudando, pois está ficando mais quente, questionário 68: "Era mais fresco"; questionário 80: "Sim a noite esta ficando mais frio e a tarde mais quente"; questionário 85: "Sim, porque está fazendo muito calor"; questionário 94: "sim porque esta ficando mais quente"; questionário 97: "Sim está quente, antes era mais frio". Não se pode desconsiderar que essa percepção também pode ser resultado da apropriação de discursos externos, seja das mídias, seja de familiares. Houve respostas curiosas, novamente apareceu à associação de fenômenos da natureza com Deus, agora por outra criança, questionário 42: "Porque Deus está voltando"; no questionário 110 uma criança provavelmente associou as mudanças climáticas às mudanças de estações durante o ano: "Sim, porque a terra gira em seu eixo"; a forma como uma criança percebe as nuvens no céu também chamou atenção, questionário 122: "Sim, a nuvem anda atrás da gente" associando esta observação às mudanças climáticas. No questionário 132, uma criança declara se lembrar do clima quando contava, ainda, com menos idade: "Sim pois quando eu era criancinha chovia muito". Em contraponto, no questionário 134 há a afirmação: "Não, todo dia está fazendo calor".

\section{Conclusões}

A complexidade dos estudos de percepção ambiental e climática impossibilita que se proceda a conclusões definitivas quanto à extensão e a qualidade da incidência da percepção. O pesquisador, mediante seu olhar especializado, pode chegar a aproximações sobre o que seja a percepção ambiental e climática e sua respectiva importância. No caso da percepção de crianças, existe uma complexidade ainda maior, pois ainda não há personalidade formada. Devido a isso, é necessário cuidado com o método utilizado para se conhecer a percepção da criança.

Neste estudo, constatou-se que não se pode afirmar que os alunos que estão inseridos em um ambiente rural demonstram percepção ambiental e climática mais apurada do que os alunos que frequentam escolas na área urbana. Esse apontamento se sustenta, sobretudo, pelas respostas obtidas na primeira questão. Além disso, como se pode observar das demais respostas, entre os questionários numerados de 40 a 142 encontram-se as respostas mais elaboradas e singulares. Essa numeração corresponde aos questionários aplicados nas escolas da área urbana do município. Destaca-se também, que todos os alunos apresentaram a mesma dificuldade: perceberem-se como pertencentes ao meio atmosférico. Ademais, em análise ao conteúdo coletado, se verificou que embora haja variação nas respostas, no geral, existe muita similaridade nas respostas das crianças.

Naturalmente, as respostas analisadas podem ser interpretadas de outras maneiras, ao passo que a riqueza do discurso da criança possibilita interpretações diversas. Entretanto, diante do objetivo de se conhecer a forma como essas crianças interpretam o meio ambiente e o clima, os métodos utilizados neste estudo mostraram-se satisfatórios.

Esta pesquisa buscou contribuir para os estudos da percepção ambiental e climática da criança. Ressaltase que o tema merece atenção, de modo que esses estudos devem ser estimulados e enriquecidos com diferentes abordagens.

Sugere-se que mais pesquisas sobre percepção ambiental e climática sejam realizadas: pesquisas com amostras menores e com um maior prazo para conclusão podem identificar a percepção do indivíduo não só por meio de questionários com perguntas pré-definidas, mas também por meio de entrevistas onde se possa privilegiar a espontaneidade e oralidade do indivíduo; no caso das crianças há ainda a possibilidade de se explorar o processo perceptivo por meio de desenhos feitos por elas.

Ante todo exposto, acredita-se que os estudos da percepção ambiental e climática podem contribuir para uma melhor compreensão da forma como o ser humano se relaciona com seu meio. 


\section{Referências}

BARROS, H.C.; PINHEIRO, J.Q. Mudanças climáticas globais e o cuidado ambiental na percepção de adolescentes: uma aproximação possível. Desenvolvimento e Meio Ambiente, Paraná, v. 40, p.189-206, abr. 2017. http://dx.doi.org/10.5380/dma.v40i0.49061.

BRASIL, G. Brasil é líder mundial na incidência de raios por ano. Net, Brasília, out. 2016. Disponível em: $\quad$ http://www.brasil.gov.br/meio-ambiente/2016/10/brasil-e-lider-mundial-na-incidencia-de-raios-porano>. Acesso em: 07 ago. 2017.

FOGAÇA, T. K.; LIMBERGER, L. Percepção ambiental e climática: estudo de caso em colégios públicos do meio urbano e rural de Toledo-PR. Revista do Departamento de Geografia - USP, São Paulo, v. 28, p.134-156, 2014. https://doi.org/10.11606/rdg.v28i0.521

GOBO, J.P.A. et al. A Influência do Vento regional na sensação térmica de pedestres em espaços urbanos abertos: estudo de caso do dento norte em Santa Maria - RS. Raega: O Espaço Geográfico em Análise, Curitiba, v. 40, p.110-129, out. 2016.

IBGE (Org.). Itajubá. Disponível em: <https://cidades.ibge.gov.br/brasil/mg/itajuba/panorama>. Acesso em: 13 dez. 2017.

KOTTEK, M. et al. World Map of Köppen-Geiger climate classification updated. Meteorologische Zeitschrift, v. 15, n. 3, p. 259-263, 2006.

OLIVEIRA, C.M.A. S. O ambiente urbano e a formação da criança. 2002. 163 f. Tese (Doutorado) Curso de Arquitetura e Urbanismo, Universidade de São Paulo, São Paulo, 2002.

OLIVEIRA, F.L.; NUNES, L.H.. A percepção climática no município de Campinas, SP: confronto entre o morador urbano e o rural. Geosul, Florianópolis, v. 43, n. 22, p.77-102, jun. 2007.

SECRETARIA MUNICIPAL DE EDUCAÇÃO DE ITAJUBÁ-MG (SEMED). Programa de intervenção pedagógica - PIP, Matriz curricular: Ciclo Complementar $-4^{\circ}$ e $5^{\circ}$ anos do Ensino Fundamenta, 2015.

REBOITA, M. S., SOUZA, D. C., RAMALHO, V., 2013. Water Balance and Aridity Index in Itajubá. In: V SIMPÓSIO INTERNACIONAL DE CLIMATOLOGIA, 2013, Florianópolis. Interação Oceano-Atmosfera: Impactos Climáticos no Presente e Cenários Futuros.

REBOITA, M. S. et al. Aspectos Climáticos do Estado de Minas Gerais (Climate Aspects in Minas Gerais State). Revista Brasileira de Climatologia, Paraná, v. 17, p.206-226, dez. 2015. http://dx.doi.org/10.5380/abclima.v17i0.41493

REBOITA, M. S.; RIONDET-COSTA, D. R. T.; SANTOS, W. V.; SILVA, B.; ASSIREU, A. T. Amigos do Clima: Atividades com alunos da educação básica. Revista Brasileira de Geografia Física, Pernambuco, v. 10, n; 6, p. 1690-1697, out. 2017.

RIBEIRO, A.A.; ZAVATTINI, J.A. Percepção climática na região das missões, Rio Grande do Sul, Brasil: método de escolha da amostra de população rural perceptivamente mais ativa em Santo Antônio das Missões, estratégia - A. in: XII SIMPÓSIO BRASILEIRO DE CLIMATOLOGIA GEOGRÁFICA, VARIABILIDADE E SUSCETIBILIDADE CLIMÁTICA: IMPLICAÇÕES ECOSSISTÊMICAS E SOCIAIS, 7, 2016, Goiânia. Anais... Goiânia: SBCG, 2016. p. 2568 - 2580.

RIBEIRO, C. R.; AFFONSO, E. P.. Avaliação da percepção ambiental de alunos do ensino fundamental residentes na bacia hidrográfica do córrego São Pedro - Juiz de Fora/MG. Boletim de Geografia, Paraná, v. 30, n. 2, p.73-85, 2 jul. 2012. http://dx.doi.org/10.4025/bolgeogr.v30i2.10077.

RODAS, C.A.; GIULIO, G.M.. Mídia brasileira e mudanças climáticas: uma análise sobre tendências da cobertura jornalística, abordagens e critérios de noticiabilidade. Desenvolvimento e Meio Ambiente, Paraná, v. 40, p.101-124, abr. 2017. http://dx.doi.org/10.5380/dma.v40i0.49002

RUOSO, D. A percepção climática da população urbana de santa cruz do Sul/RS. Raéga: O Espaço Geográfico em Análise, Curitiba, v. 25, p.64-91, 2012.

SANTOS, W. V.; REBOITA, M. S. Percepção ambiental e climática: estudo de caso em escolas públicas em áreas urbanas e rurais de Itajubá-MG. In: SEMINÁRIO DE RECURSOS NATURAIS, 4.; 2017, Itajubá: UNIFEI, 2017.

SARTORI, M.G.B.. Clima e Percepção Geográfica: Fundamentos teóricos à percepção climática e à bioclimatologia humana. Santa Maria: Pallotti, 2014. 192 p. 
SPECIAN, V.; PAIVA, D.G.; ROCHA, T. Percepção climática: as chuvas e tempo para os moradores de Arenópolis - Goiás. In: ENCONTRO NACIONAL DE GEÓGRAFOS. 2016, São Luís - Ma. VIII Encontro Nacional de Geógrafos - A construção do Brasil: Geografia, ação política e democracia, 2016, São Luís: UEG, 2016. p. 56 - 67.

TOMINAGA, L. K; S., J; A., R. (Orgs.) Desastres Naturais: conhecer para prevenir. $1 . e d / 2^{\circ}$ reimpressão. São Paulo: Instituto Geológico, 2011. 196 pp.

TUAN, Y. Paisagem do medo. Trad. Lívia de Oliveira. São Paulo: Editora UNESP, 2005.

TUAN, Y. Topofilia: um estudo da percepção, atitudes e valores do meio ambiente. Tradução prefácio e notas: Lívia de Oliveira. São Paulo: DIFEL, 2012. 